\title{
Risks and rewards of increasing patient access to medical records in clinical ophthalmology using OpenNotes
}

\author{
Jake E. Radell $\mathbb{D}^{1,6}{ }^{凶}$, Jasmine N. Tatum ${ }^{2,6}$, Chen-Tan Lin $^{3}$, Richard S. Davidson ${ }^{4}$, Jonathan Pell ${ }^{3}$, Amber Sieja ${ }^{3}$ and Albert Y. Wu ${ }^{5}$
}

(c) The Author(s) 2021

BACKGROUND: The implementation of OpenNotes and corresponding increase in patient access to medical records requires thorough assessment of the risks and benefits of note-sharing. Ophthalmology notes are unique among medical records in that they extensively utilize non-standardized abbreviations and drawings; they are often indecipherable even to highly-educated clinicians outside of ophthalmology. No studies to date have assessed ophthalmologist perceptions of OpenNotes.

METHODS: A cross-sectional study was conducted from 4/28 to 5/12/2016. A survey was distributed to 30 clinicians (25 ophthalmologists, three optometrists, two nurses) in the University of Colorado's Department of Ophthalmology to evaluate provider attitudes towards granting patients access to online medical records.

RESULTS: Many clinicians felt patients would have difficulty understanding their records and may be unnecessarily alarmed or offended by them. Some clinicians worried their workload would increase and feared having to change the way they document. Perceived benefits of OpenNotes included improving patient understanding of their medical conditions, strengthening patient-physician trust, and enhancing patient care. Many perceived risks and benefits of note-sharing were associated with conceptions of the ideal clinician-patient relationship.

CONCLUSIONS: Clinicians in ophthalmology perceived both benefits and consequences of increasing patient access to ophthalmic records, and there were significant correlations between these perceptions and their conceptions of the clinician-patient relationship. This is the first study to assess potential ophthalmology provider attitudes toward sharing ophthalmic records. Although limited in sample size and power, this study demonstrates some ways patient-accessible ophthalmic records can affect the clinical practice of ophthalmology and emphasizes the unique challenges of OpenNotes in ophthalmology.

Eye (2022) 36:1951-1958; https://doi.org/10.1038/s41433-021-01775-9

\section{INTRODUCTION}

Patients' ability to access their medical records has been a key component of the evolution of a more patient-centered healthcare system, and development of programs that enable easy access to electronic medical records has facilitated this evolution. In particular, the "OpenNotes" program has grown rapidly over the past several years, allowing patients to view the notes written by their providers via an online portal. Per their website, OpenNotes is "an international movement committed to spreading and studying the effects of transparent communication among patients, families and clinicians". In practice, adoption of OpenNotes by healthcare systems involves dramatically increasing the accessibility of electronic medical record notes to patients using patient-facing online portals. OpenNotes is not in itself a method of note-sharing, but rather, a movement pushing for health systems to use existing electronic medical record-based tools to openly share notes with patients. As of 2020, over 50 million patients in the United States had access to their medical records through patient portals [1]. This number should further increase following the 4/5/2021 milestone set by the 21st Century Cures Act in the US [2].
Several studies have shown that increasing patient access to medical records can enhance doctor-patient communication, reduce errors, and improve healthcare quality [3-7]. Despite these potential benefits, enabling patients to view their medical records may also have negative consequences. Preliminary studies found that access to medical records has the potential to unnecessarily concern or confuse patients, and many clinicians are concerned that such access will increase their workload if patients contact the office with questions about their records [8-18]. Additionally, there is concern that clinicians may change the way they document if they know the records will be viewed by patients, potentially rendering them less useful to healthcare professionals and patients alike $[18,19]$. However, more recent studies indicate that after the implementation of note-sharing, clinician concerns over an increase in workload significantly decrease and most clinicians are in favor of sharing notes with patients [20-22]. In fact, the vast majority of clinicians surveyed after using OpenNotes agreed that note-sharing is a good idea and increases patient engagement, with $44 \%$ of clinicians changing their opinion on OpenNotes from negative to positive after implementation [21, 22].

\footnotetext{
${ }^{1}$ Department of Ophthalmology, Icahn School of Medicine at Mount Sinai, New York, NY, USA. ${ }^{2}$ Department of Psychiatry, Stanford University School of Medicine, Stanford, CA, USA. ${ }^{3}$ Department of Medicine, University of Colorado School of Medicine, Aurora, CO, USA. ${ }^{4}$ Department of Ophthalmology, University of Colorado School of Medicine, Aurora, CO, USA. ${ }^{5}$ Department of Ophthalmology, Stanford University School of Medicine, Stanford, CA, USA. ${ }^{6}$ These authors contributed equally: Jake E. Radell, Jasmine N. Tatum.

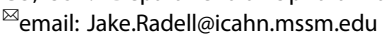


The risks and benefits of patient access to online medical records have been studied previously in several fields of medicine, but not in ophthalmology. Increased access to medical records poses unique challenges in ophthalmology for multiple reasons. First, clinical ophthalmology has a complex workflow that involves various medical personnel, including technicians, photographers, nurses, optometrists, and physicians. Evaluations typically require numerous procedures and tests involving different imaging modalities and measurement devices at each visit. Most of these modalities and measurements yield results that are not readily interpretable by patients. The multidimensional nature of clinical ophthalmology considerably complicates medical records and may make them less decipherable to patients. Second, clinical ophthalmology is a fast-paced, high-volume outpatient field. With hundreds of patients to see each week, clinicians may have less time to explain their medical notes to patients. Third, ophthalmology notes are written using a large lexicon and a multitude of abbreviations (both standardized and unstandardized) [23-27]. It can be difficult for non-ophthalmologist physicians to understand ophthalmology notes, let alone patients without medical training. While there is an argument that ophthalmologists should work to increase readability of their documentation rather than continue to use often unintelligible acronyms, a movement towards such a large change in documentation patterns has not yet gained strength and would certainly take years to implement. In the meantime, ophthalmology notes remain incomprehensible to the vast majority of people. Lastly, ophthalmology is a visuallyoriented field and many practitioners rely heavily on drawings and annotations created with visual templates. Not only are these drawings routinely left out from online medical notes, but, if they are included, they are often uninterpretable to the untrained eye. Despite the difficulties of interpreting ophthalmology notes, the only known study surveying ophthalmology patients on this issue found that patients strongly desired access to their ophthalmology notes and believed such access would benefit their care [28]. This finding is in keeping with those of non-ophthalmology studies showing that patients perceive OpenNotes as beneficial to their care and their health $[29,30]$. In the context of recent legislative changes and well-documented patient desire to access notes, it is essential that the medical community gain a greater understanding of clinician perceptions of note-sharing, particularly in unique fields such as ophthalmology.

Here we administered a survey to faculty ophthalmologists at the Department of Ophthalmology at the University of Colorado Hospital to better understand the unique implications of encouraging patient access to electronic ophthalmic medical records.

\section{METHODS}

From April 28 to May 12, 2016, a questionnaire measuring perceived risks and benefits of increasing patient access to online medical records was distributed by e-mail to 30 clinicians including ophthalmologists, nurses, and optometrists, in the Department of Ophthalmology at University of Colorado. Responses were accepted only before implementation of OpenNotes. The questionnaire included questions assessing respondents' beliefs about clinician-patient relationships. A composite score assessed each clinicians' general perceptions of sharing medical records with patients and was calculated by averaging the responses to the questionnaire. The questionnaire had been used in previous studies and had been reported to have strong reliability and validity $[18,31,32]$. No identifying information was obtained. Both University of Colorado and Mount Sinai approved the study, which was exempted from Institutional Review Board approval.

The questionnaire also gathered demographic information about respondents including age, gender, years in practice, highest degree earned, and specialty.

A Spearman's correlation test (alpha $=0.05$ ) was used to determine whether demographic characteristics or conceptions of the clinician-patient relationship were associated with perceived risks or benefits of increasing patient access to medical records.

\section{RESULTS}

\section{Participant characteristics}

Out of 30 clinicians recruited, 29 participated in the study $(96.7 \%$ response rate). Of the 29 participants for whom data was available, 9 (31\%) were female and mean age was 47.18 (SD 10.47; range 31-66). Twenty-four of 29 clinicians (82.8\%) had MD degrees and identified themselves as "ophthalmologists" (Table 1). More than half $(55 \%)$ of clinicians had been in practice for over 15 years, and all clinicians reported practicing for more than 3 years. Two clinicians (6.9\%) reported routinely sending copies of clinical notes to patients.

\section{Perceived risks and benefits of using patient-accessible online} medical records

Figure 1 summarizes mean responses on a Likert Scale (from 1 to 4: strongly disagree to strongly agree) to questions assessing general expectations of clinicians regarding encouraging patients to access their ophthalmology medical records online.

All clinicians surveyed identified potential negative consequences. Many believed that patients would find the medical record confusing and have a hard time interpreting test and imaging reports $(69 \%$ and $79.3 \%$ respectively). Most clinicians $(75.9 \%)$ believed patients would worry more if they could access their medical records, and $89.7 \%$ predicted that their patients would be offended by some things written in their record. $82.8 \%$ were concerned that patients would contact their practice with more questions between visits, and $86.2 \%$ were concerned about having to document differently in the medical record. $55.2 \%$ of clinicians were worried their workload would substantially increase. Although many clinicians expressed concern about OpenNotes, survey respondents also believed note-sharing could

\begin{tabular}{|c|c|}
\hline Characteristic & Frequency (\%) \\
\hline Age, mean $\pm S D$ [range] ${ }^{a}$ & $47.2 \pm 10.5[31-66]$ \\
\hline \multicolumn{2}{|l|}{ Gender } \\
\hline Male & $20(69)$ \\
\hline Female & $9(31)$ \\
\hline \multicolumn{2}{|l|}{ Clinician title } \\
\hline Physician & $24(82.8)$ \\
\hline Other clinician & $5(17.2)$ \\
\hline \multicolumn{2}{|l|}{ Years practicing } \\
\hline Under 1 year & $0(0)$ \\
\hline Between 1 and 3 years & $0(0)$ \\
\hline Between 3 and 5 years & $1(3.4)$ \\
\hline Between 5 and 10 years & $8(27.6)$ \\
\hline Between 10 and 15 years & $4(13.8)$ \\
\hline Between 15 and 20 years & $6(20.7)$ \\
\hline Between 20 and 30 years & $3(10.3)$ \\
\hline Over 30 years & $7(24.1)$ \\
\hline Practice in a clinical setting & $20(100)$ \\
\hline $\begin{array}{l}\text { Routinely sends copies of clinical notes to } \\
\text { patients }\end{array}$ & $2(6.9)$ \\
\hline \multicolumn{2}{|c|}{$\begin{array}{l}\text { a Data regarding age was available for } 28 \text { of the } 29 \text { participants. One } \\
\text { participant reported that he was } 10 \text { years old and had been a practicing } \\
\text { Ophthalmologist for } 60 \text { years. Due to this inconsistency and suspected } \\
\text { error in reporting, he was excluded from all data analysis involving age. }\end{array}$} \\
\hline
\end{tabular}




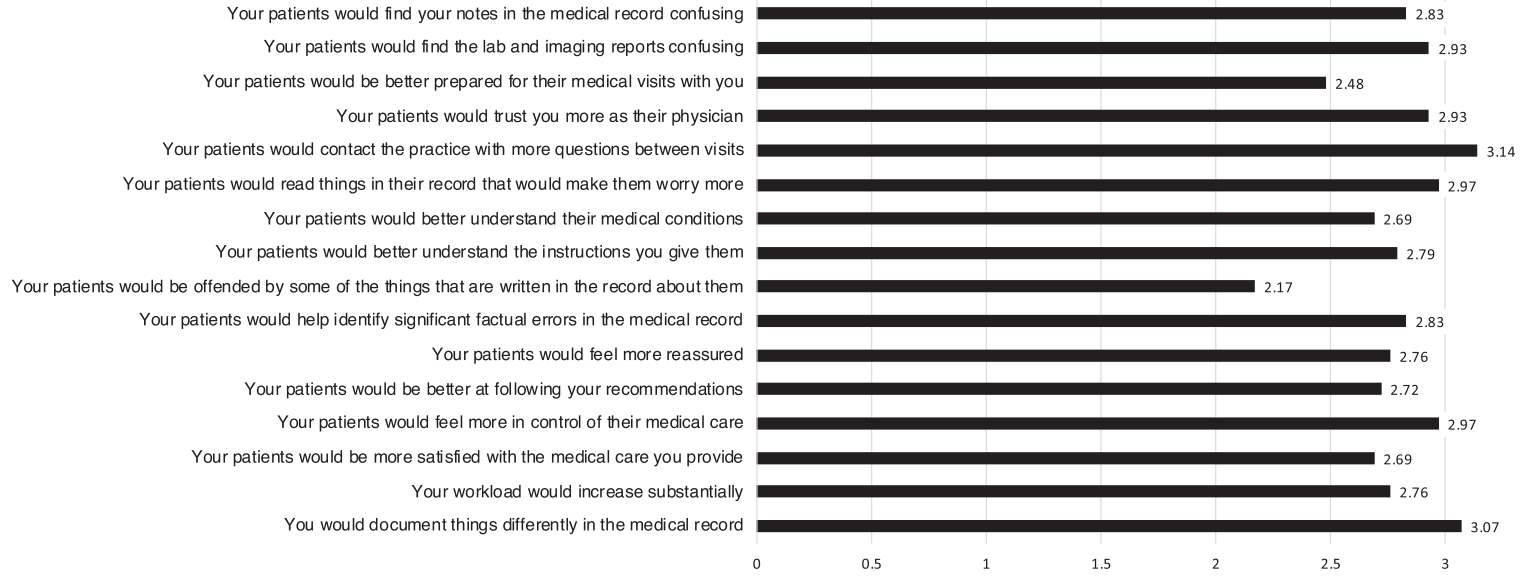

Fig. 1 Perceived risks and benefits of using patient-accessible online ophthalmic medical records (Mean). Responses are graded on a Likert scale from 1 (strongly disagree) to 4 (strongly agree). The length of each bar indicates the mean response for each question.

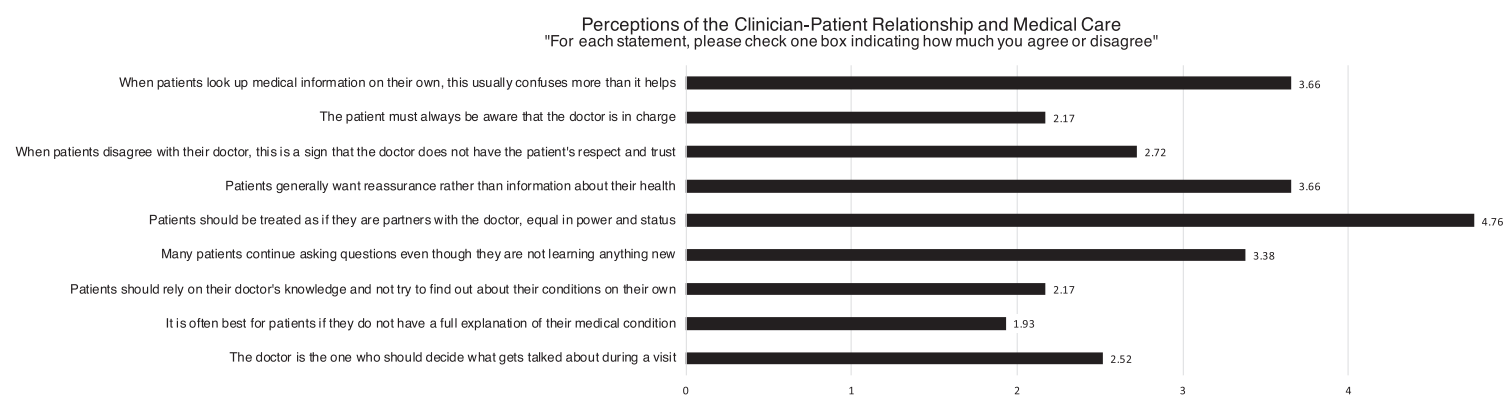

Fig. 2 Perceptions of the clinician-patient relationship (Mean). Responses are graded on a Likert scale from 1 (strongly disagree) to 6 (strongly agree).

be beneficial. $48.3 \%$ of clinicians believed patients would be better prepared for medical visits, and $82.8 \%$ believed sharing medical records would increase patient-physician trust. Many clinicians felt that their patients would better understand their medical conditions (65.6\%), better comprehend instructions given $(72.4 \%)$, and be better able to follow medical recommendations (65.5\%). $79.4 \%$ believed patients would be able to help identify significant factual errors in the medical record, and $89.7 \%$ thought patients would feel more in control of their medical care. When asked if sharing medical records would increase patient satisfaction with medical care, $69 \%$ agreed that it would.

\section{Assessing clinician-patient relationships}

Figure 2 summarizes mean responses on a Likert Scale (from 1 to 4: strongly disagree to strongly agree) to questions assessing attitudes regarding the clinician-patient relationship. $89.7 \%$ felt that patients should be treated as partners with the doctor, equal in power and status. All but one clinician disagreed that the patient must always be aware the doctor is in charge (96.5\%), and $75.9 \%$ also disagreed that the doctor should be the one deciding what gets discussed during visits. $20.7 \%$ of clinicians felt patientdoctor disagreements are a sign of patients' disrespect and mistrust. $93.1 \%$ felt it was best if patients have full explanations of their medical conditions, yet when asked if patients generally want reassurance rather than information about their health, $55.2 \%$ agreed that patients preferred reassurance over information. 55.2\% felt that when patients look up medical information on their own, it usually confuses them more than it helps, yet $96.6 \%$ disagreed that patients should rely on their doctor's knowledge and refrain from researching their conditions. $51.7 \%$ felt that many patients continued asking questions even though they are not learning anything new.

\section{Factors influencing perceptions}

Clinicians' responses to potential risks and benefits of providing patients with access to online ophthalmic medical records, as summarized by composite score of clinician perspectives, were not significantly associated with gender, age, years in practice, or the clinician's role.

Some perceptions of the clinician-patient relationship were found to be significantly associated with perceived benefits or risks of increasing patient access to online medical record (Tables 2-4). The degree to which doctors felt physicians should decide what gets discussed during a medical visit and the degree to which they believed it was best if patients did not have a full explanation of their records were both negatively correlated $(p<0.01, R=-0.519$; $p<0.05, R=-0.430$ ) with the belief that patients would better understand instructions if they had access to their medical records. The extent to which clinicians felt patient-physician disagreements are signs of disrespect/mistrust was negatively correlated with fear of an increase in workload ( $p<0.05, R=-0.465$ ). The extent to which clinicians felt patient-physician disagreements are signs of disrespect/mistrust was positively correlated with feeling the patient would be better prepared for visits $(p<0.05, R=+0.434)$, better understand medical conditions $(p<0.01, R=+0.525)$, and better understand instructions given to them $(p<0.05, R=$ $+0.443)$. The degree to which clinicians believed patients should realize the doctor is always in charge was negatively correlated with worry that patients would be offended by what is written in medical records ( $p<0.05, R=-0.385$ ). Finally, the degree to which 


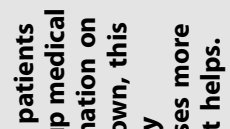

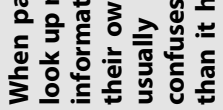

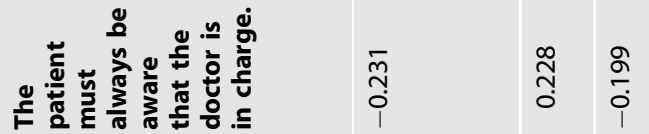

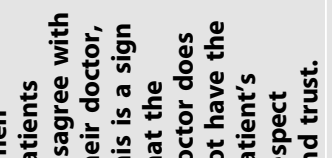

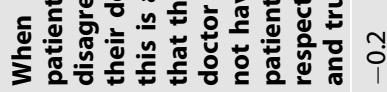

\begin{tabular}{l|l|l}
\multirow{N}{*}{} & $\frac{n}{0}$ \\
& $\frac{n}{0}$
\end{tabular}

مิ

$\begin{array}{llll}\hat{8} & 0 & n & n \\ 0 & 0 & 0 & 0 \\ 0 & 0 & 0\end{array}$

$\underset{\tilde{n}}{0}$

\begin{tabular}{ll}
\multirow{2}{*}{} & $\bar{n}$ \\
0 & 0 \\
0 & 1
\end{tabular}

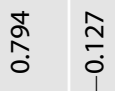

in $\quad \stackrel{n}{m}$

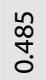

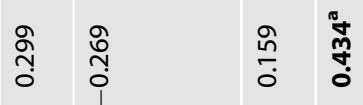

$\stackrel{\substack{0 \\ 0}}{\frac{\operatorname{Ln}}{0}}$

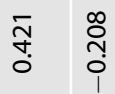

กิ

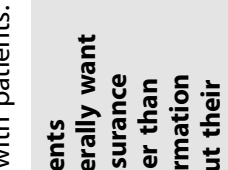

ع

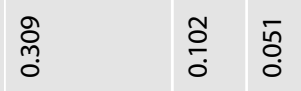

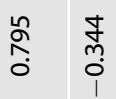

$\begin{array}{ll}\infty \\ 0 \\ 0 & \stackrel{\infty}{0} \\ 0 & 0\end{array}$

\begin{tabular}{ll}
$\frac{\pi}{0}$ & $\overline{0}$ \\
\hline & 0
\end{tabular}

ผั

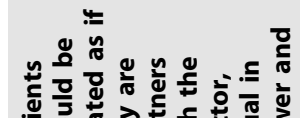

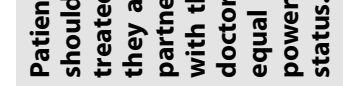

ชิ

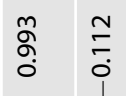

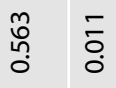

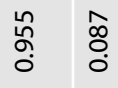

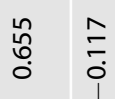

实

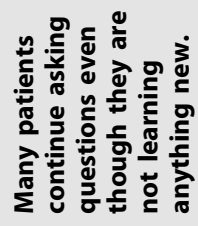

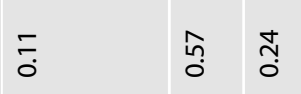

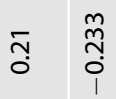

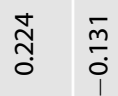

\begin{tabular}{ll}
$\infty$ & \multirow{2}{0}{} \\
$\stackrel{0}{0}$ & 0 \\
0 & 0
\end{tabular}

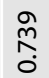

즘

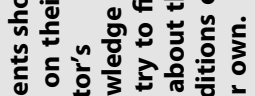

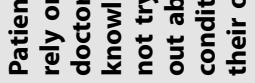

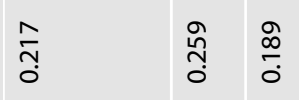

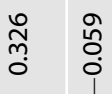

$\begin{array}{ll}\stackrel{0}{n} & \overline{0} \\ 0 & 0 \\ 0 & 0\end{array}$

$\begin{array}{ll}\stackrel{n}{\hat{\sigma}} & \hat{む} \\ 0 & 0\end{array}$

$\frac{\pi}{0}$

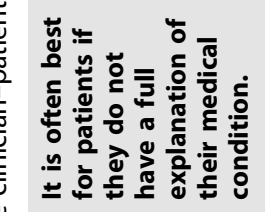

\begin{tabular}{l|l|l}
$m$ & $\infty$ & $\infty$ \\
$m$ & 0 & 0 \\
0 & 0 & 0
\end{tabular}

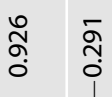

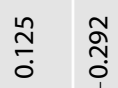

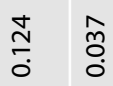

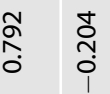

$\begin{array}{ll}\infty & 8 \\ \text { तै } & 0 \\ 0 & 0\end{array}$

$\underset{N}{N} \stackrel{\overbrace{}}{N}$

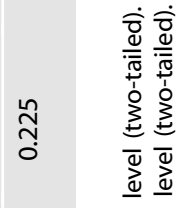

능 - 


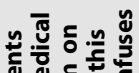

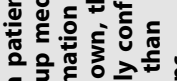

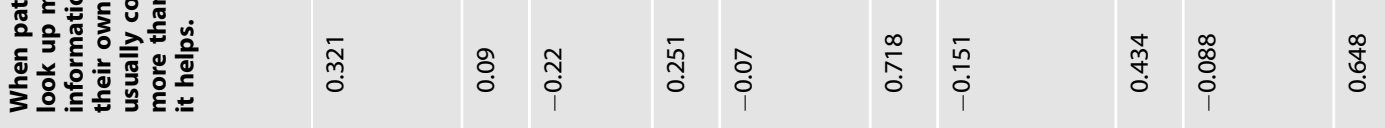

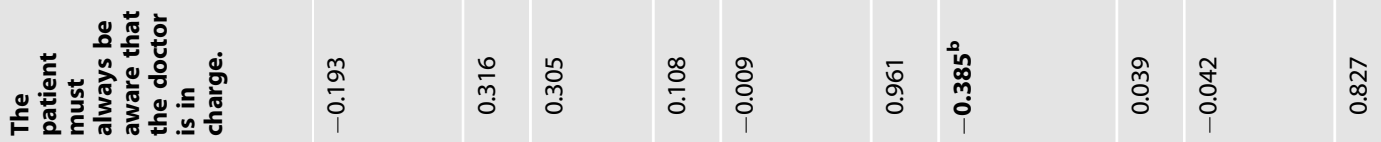

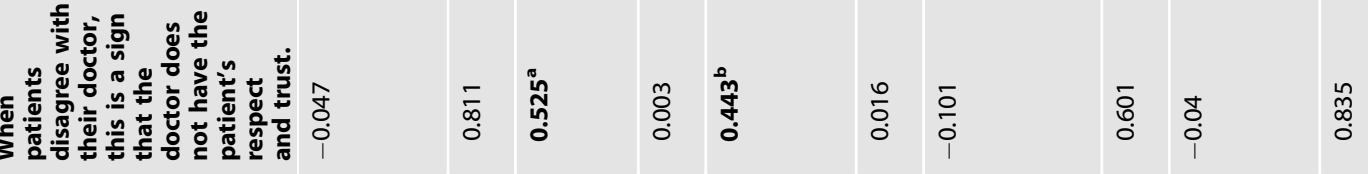

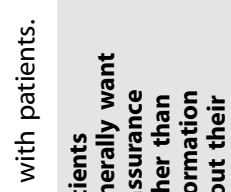

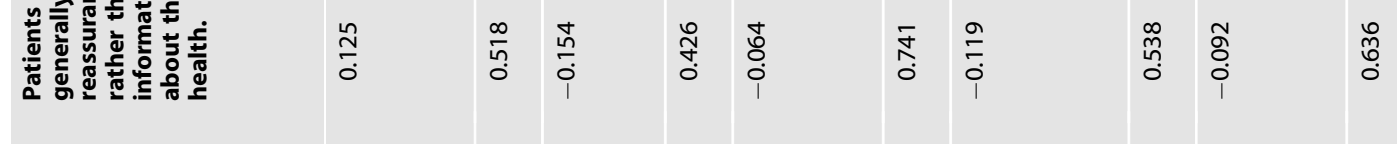

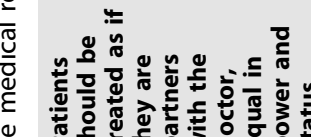

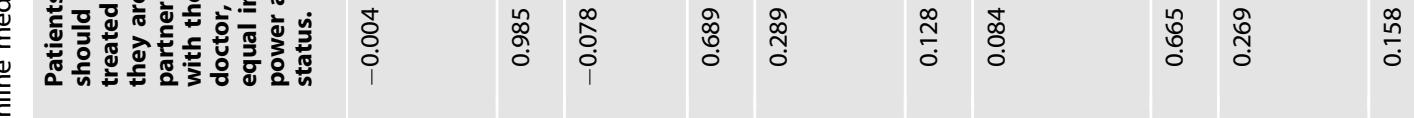

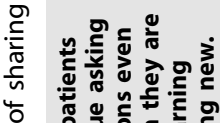

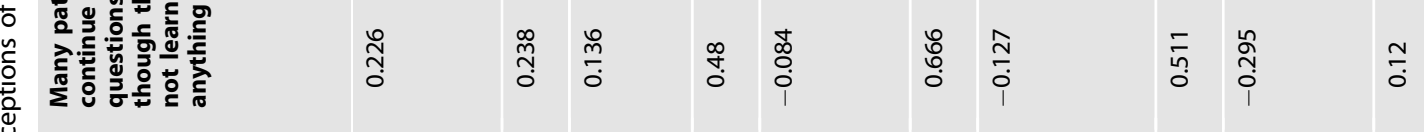

\section{㝘.}

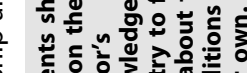

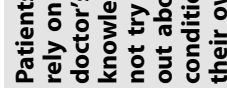

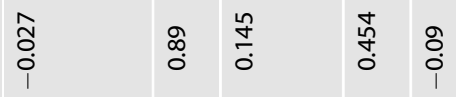

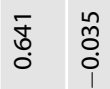

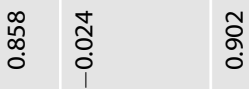

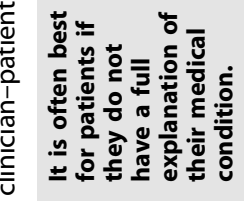

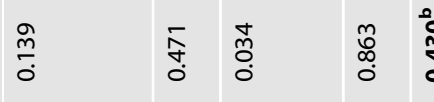

$\stackrel{\infty}{\circ} \stackrel{\infty}{0}$

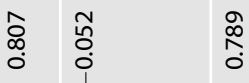

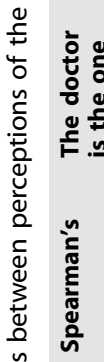

ปั่

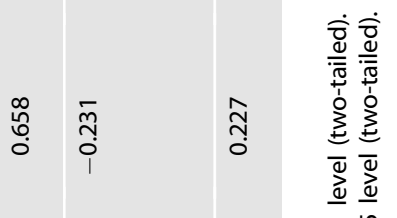

둥.

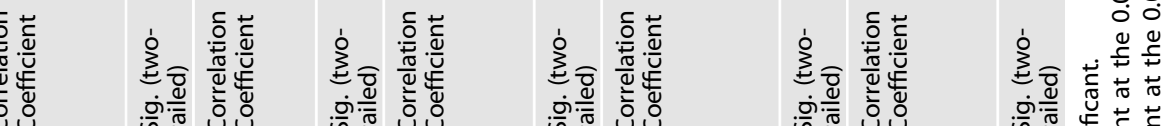

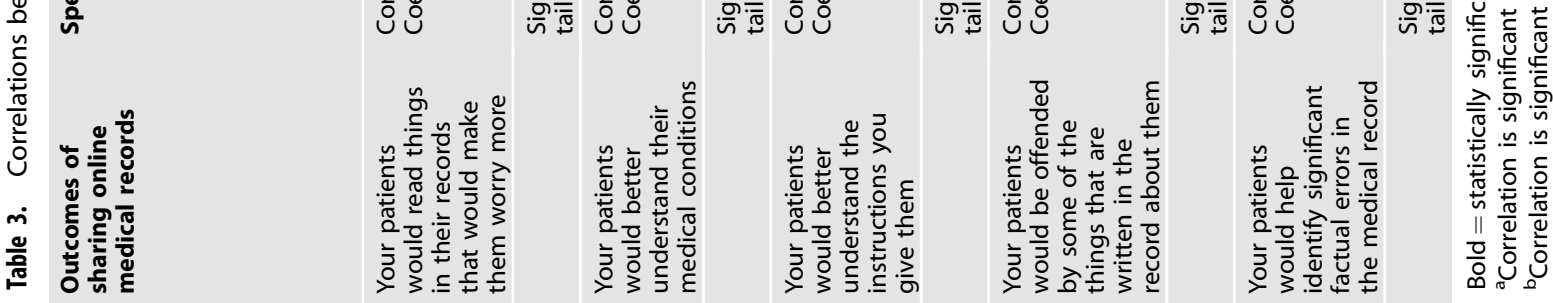




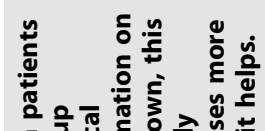

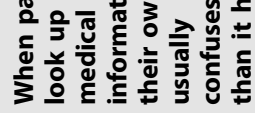

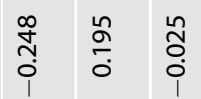

$\begin{array}{lll}\infty & 0 \\ 0 & m & 0 \\ 0 & m & 0 \\ 0 & 1 & 1\end{array}$

$\underset{0}{\stackrel{0}{0}} \frac{1}{\dot{0}}$

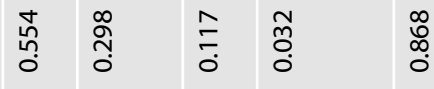

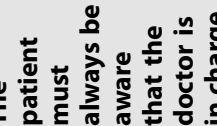

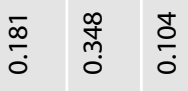

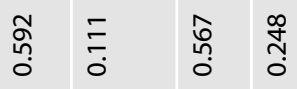

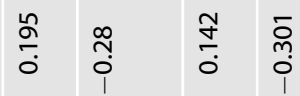

$\stackrel{m}{E}$

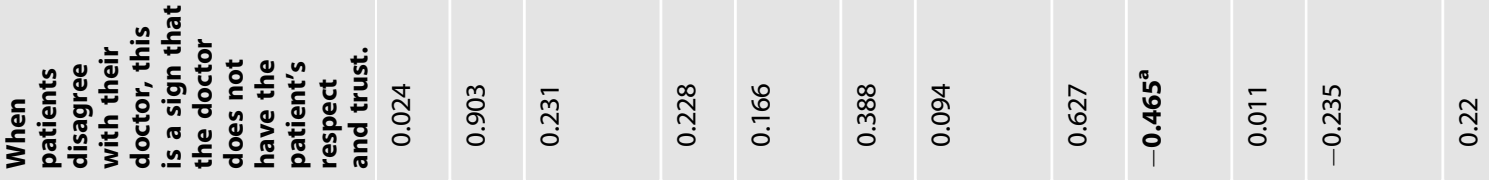

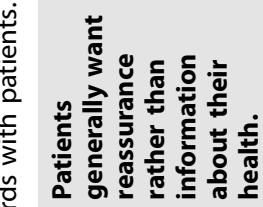

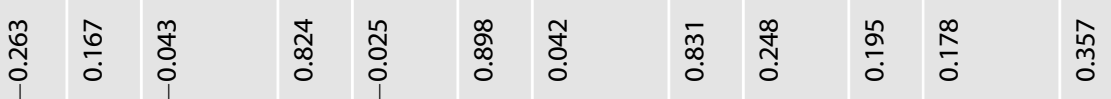

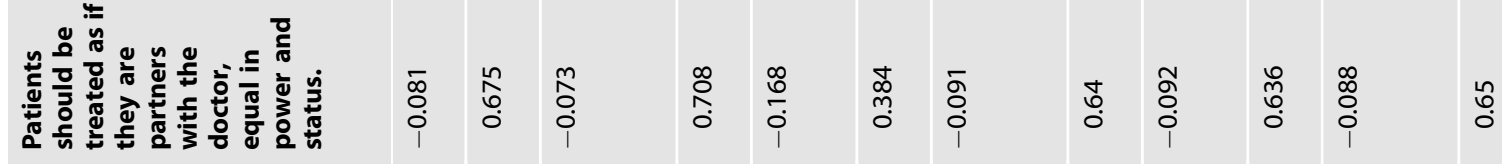

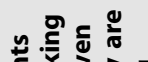

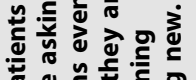

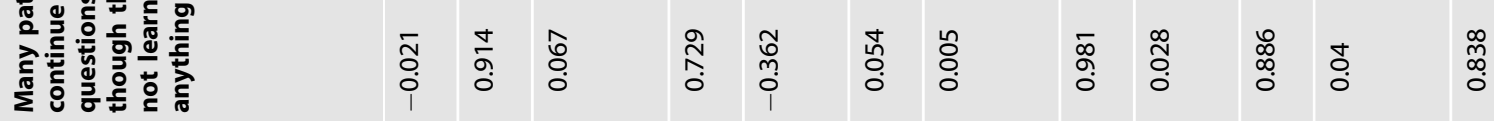

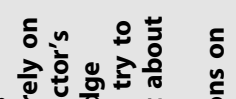

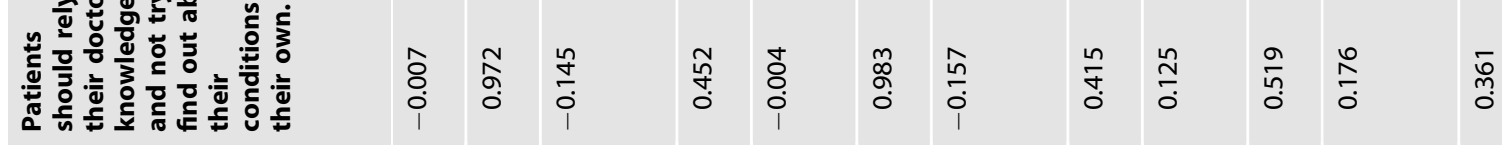
㟥:

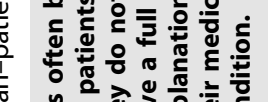

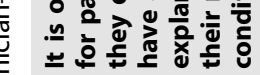

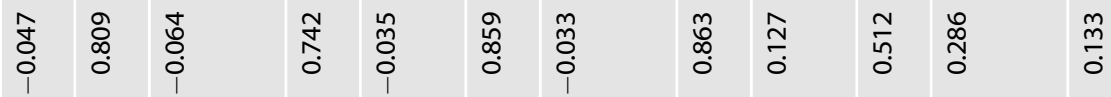

\begin{tabular}{|c|c|c|c|c|c|c|c|c|c|c|c|c|}
\hline 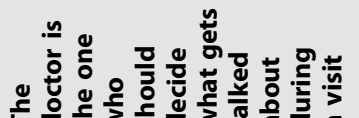 & 0 & - & $\begin{array}{l}\text { fo } \\
0 \\
0\end{array}$ & $\begin{array}{l}\hat{N} \\
\infty \\
0\end{array}$ & $\begin{array}{l}\text { ̊̊̀ } \\
\text { ò }\end{array}$ & 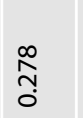 & $\stackrel{\stackrel{N}{\sim}}{0}$ & $\hat{\tilde{n}}$ & $\begin{array}{l}\stackrel{\leftrightarrow}{0} \\
\stackrel{0}{0}\end{array}$ & $\frac{n}{0}$ & 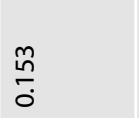 & ปิ \\
\hline 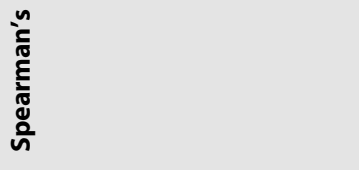 & 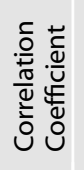 & 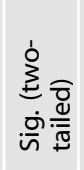 & 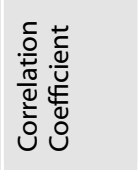 & 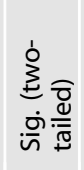 & 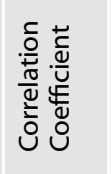 & 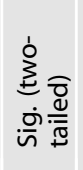 & 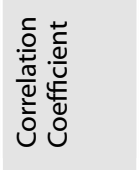 & 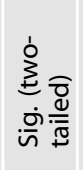 & 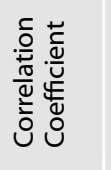 & 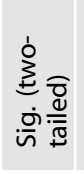 & 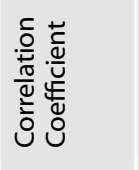 & 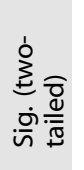 \\
\hline 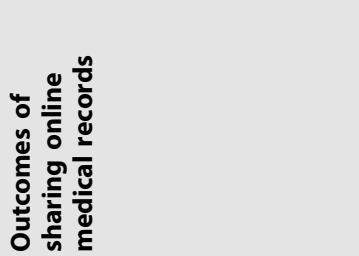 & 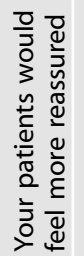 & & 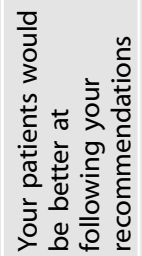 & & 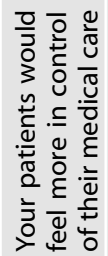 & & 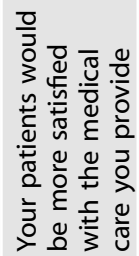 & & 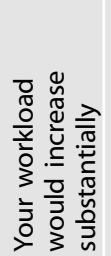 & & 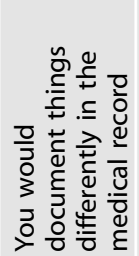 & \\
\hline
\end{tabular}


physicians felt patients who look up information on their own are more often confused than helped was negatively correlated with feeling the patient would be better prepared for medical visits $(p<$ $0.01, R=-0.492)$.

\section{DISCUSSION}

The results of this study suggest that implementation of patientaccessible medical records may be uniquely challenging in ophthalmology. The main obstacle appears to be patient comprehension of medical records. Nearly $80 \%$ of University of Colorado ophthalmology clinicians believed patients would have difficulty interpreting ophthalmic records. This majority of clinicians is especially striking when compared to a previous study at University of Colorado showing that only 14\% of Cardiology clinicians believed patients would have difficulty interpreting online cardiovascular medical records [18]. The perceived decrease in patient comprehension could be attributed to factors that make ophthalmic medical records difficult to understand, including their multidimensional nature, complicated and unstandardized abbreviations, and reliance on visual drawings and annotations.

Regardless of the source of this perceived comprehension barrier, it is imperative that ophthalmologists work to reduce this barrier in the era of legally mandated note-sharing which began on $4 / 5 / 2021$. Patients will be reading ophthalmologist notes moving forward, so it falls to the ophthalmologist community to work toward making their notes comprehensible to patients and clinical colleagues without an abbreviation dictionary on hand. Technology may be of help in this process, as with electronic medical record systems approaching universal adoption, the tools for automatically translating ophthalmic abbreviations should become more widely available and routinely used.

Although this study corroborates previous research in indicating OpenNotes' potential to improve clinician-patient communication, patient adherence, and patient empowerment, it is unclear how these benefits will manifest in ophthalmology given the large comprehension barrier. Additionally, clinicians surveyed perceived a variety of potential drawbacks of sharing medical records with patients, including increasing patient confusion, worry, and stress, increasing clinician workload, and changing the way clinicians document encounters, potentially jeopardizing the integrity and usefulness of medical records. Although, these concerns have been echoed by clinicians in other departments, the percentage of clinicians who feared these negative consequences was greater in Ophthalmology, suggesting that ophthalmology is distinct from other specialties with respect to implementation of patientaccessible medical records.

Several perceptions surrounding physician-patient relationships were associated with ideas about increasing accessibility of medical records. Clinicians who viewed patient-physician arguments as signs of mistrust saw more benefits of notes-sharing; they were significantly less likely to worry about increases in their workload, and more likely to believe patients would be better prepared for visits and better understand their medical conditions and instructions. In contrast, there was a correlation between physicians believing the doctor should always be in charge and physicians seeing negative consequences of note-sharing. Those who believed they should be in charge were significantly more concerned that patients would be offended by note contents. These correlations suggest that physician perceptions regarding the doctor-patient relationship and perceptions regarding patient access to medical records are intimately related. Changing access to patient medical records could alter the clinician-patient relationship, an important pillar of clinical ophthalmology.

This study is limited primarily by small sample size, which limits statistical power. Additionally, because this study only sampled the perceptions of clinicians, not patients, it is unable to assess some potential benefits and risks that note-sharing might have in ophthalmology. Clinician and patient perspectives on whether patients should have access to medical records are often discordant; it is imperative to not only understand how these perspectives diverge, but why.

Importantly, the beliefs assessed in this study were recorded in 2016, before the clinicians began using OpenNotes. Ideally, perceptions about OpenNotes would be assessed before and after its implementation, but this was not feasible here. If surveyed after using OpenNotes, it is likely that some ophthalmologist concerns would be assuaged, while others may be magnified. In 2021, after 5 years of use of OpenNotes, clinical leadership at University of Colorado reports that no significant concerns have been raised by patients despite the fears of the ophthalmologists surveyed in 2016 prior to OpenNotes implementation (ChenTan Lin, MD, e-mail communication, June 2021). Future studies should assess patient comprehension of online ophthalmic records and examine how perceptions of note-sharing change after ophthalmologists become accustomed to patient-accessible records. A growing body of literature indicates that after implementation of OpenNotes, clinicians generally view notesharing as a net positive [1,20-22], but is important that this question is explored in the field of ophthalmology specifically.

Despite its limitations, this study offers important insights on how increasing patient access to medical records may affect healthcare delivery and doctor-patient relationships. By identifying provider-perceived risks and benefits of providing patients access to online ophthalmic records, this study sets the foundation for future investigation on how such unprecedented access can impact the patient-physician relationship, patient trust, clinical outcomes, and the ophthalmologist's practice. Finally, this study suggest that ophthalmology clinicians may have fears and concerns regarding the implementation of OpenNotes that differ significantly from those of other clinicians. As such, health systems implementing OpenNotes should recognize the unique challenges that note-sharing poses in ophthalmology, educate ophthalmology providers on the benefits of note-sharing, and collaborate with these providers to work toward the goal of making notes more comprehensible to patients.

\section{SUMMARY}

\section{What was known before}

- The recent development and use of informational programs that facilitate patients' access to online medical records has made it imperative to uncover the potential risks and benefits of such programs in the field of ophthalmology.

- Ophthalmology notes are unique among medical notes in that they extensively utilize non-standardized abbreviations and drawings by physicians in a way that is often indecipherable even to highly-educated clinicians outside of ophthalmology.

What this study adds

- Ophthalmology clinicians perceive many benefits to notesharing but also have fears about OpenNotes that differ significantly from those of other clinicians.

- The unique nature of ophthalmological documentation may augment challenges of OpenNotes implementation in ophthalmology.

\section{REFERENCES}

1. OpenNotes. Effects of OpenNotes. 2021. https://www.opennotes.org/effects-ofopennotes-faqs/ Accessed 12 May 2021. 
2. Delbanco T, Wachenheim D. Open notes: new federal rules promoting open and transparent communication. Jt Comm J Qual Patient Saf. 2021;47:207-9. https:// doi.org/10.1016/j.jcjq.2021.02.004.

3. Carter M. Should patients have access to their medical records? Med J Aust. 1998;169:596.

4. Shenkin BN, Warner DC. Giving the patient his medical record: a proposal to improve the system. N Engl J Med. 1973;289:688-92.

5. Westin AF. Medical records: should patients have access? Hastings Cent Rep. 1977;7:23-8.

6. Kirby BJ. Patient access to medical records. J R Coll Physicians Lond. 1991;25:240-2.

7. Short D. Some consequences of granting patients access to consultants' records. Lancet. 1986;1:1316-8. https://doi.org/10.1016/s0140-6736(86)91232-8.

8. Seitz JF, Ward A, Dobbs WH. Granting patients access to records: the impact of the Privacy Act at a federal hospital. Hosp Community Psychiatry. 1978;29:288-9. https://doi.org/10.1176/ps.29.5.288.

9. Andersen T, Jorgensen G. Danish experience of statutory right of patients to access hospital records. Lancet. 1988;332:1428.

10. Jones RB, McGhee SM, McGhee D. Patient on-line access to medical records in general practice. Health Bull. 1992;50:143-50.

11. Baldry M, Cheal C, Fisher B, Gillett $M$, Huet V. Giving patients their own records in general practice: experience of patients and staff. Br Med J. 1986;292:596-8.

12. Gill MW, Scott DL. Can patients benefit from reading copies of their doctors' letters about them? Br Med J. 1986;293:1278.

13. Golodetz A, Ruess J, Milhous RL. The right to know: giving the patient his medical record. Arch Phys Med Rehabil. 1976:57:78-81.

14. Stevens DP, Stagg R, Mackay IR. What happens when hospitalized patients see their own records. Ann Intern Med. 1977;86:474-7.

15. Draper J, Field S, Thomas H, Hare MJ. Should women carry their antenatal records? Br Med J. 1986;292:603.

16. Lovell A, Zander LI, James CE, Foot S, Swan AV, Reynolds A. The St. Thomas's Hospital maternity case notes study: A randomised controlled. trial to assess the effects of giving expectant mothers their own maternity case notes. Paediatr Perinat Epidemiol. 1987;1:57-66.

17. Bernadt M, Gunning L, Quenstedt M. Patients' access to their own psychiatric records. BMJ. 1991;303:967.

18. Earnest MA, Ross SE, Wittevrongel L, Moore LA, Lin CT. Use of a patient-accessible electronic medical record in a practice for congestive heart failure: patient and physician experiences. J Am Med Inform Assoc. 2004;11:410-7.

19. Ross AP. The case against showing patients their records. Br Med J. 1986;292:578.

20. Delbanco T, Walker J, Bell SK, Darer JD, Elmore JG, Farag N, et al. Inviting patients to read their doctors' notes: a quasi-experimental study and a look ahead. Ann Intern Med. 2012;157:461-70. https://doi.org/10.7326/0003-4819-157-7-201210020-00002.

21. DesRoches CM, Leveille S, Bell SK, Dong ZJ, Elmore JG, Fernandez L, et al. The views and experiences of clinicians sharing medical record notes with patients. JAMA Netw Open. 2020:3:e201753. https://doi.org/10.1001/jamanetworkopen.2020.1753.

22. Ralston JD, Yu O, Penfold RB, Gundersen G, Ramaprasan A, Schartz EM. Changes in clinician attitudes toward sharing visit notes: surveys pre-and post-implementation. J Gen Intern Med. 2021:1-7. https://doi.org/10.1007/s11606-02106729-1.

23. Sanguansak T, Morley MG, Yospaiboon Y, Lorch A, Hedt B, Morley K. The impact of preprinted prescription forms on medication prescribing errors in an ophthalmology clinic in northeast Thailand: a non-randomised interventional study. BMJ Open. 2012;2:e000539.

24. Holley CD, Lee PP. Primary care provider views of the current referral-to-eye-care process: focus group results. Investig Ophthalmol Vis Sci. 2010;51:1866-72.

25. Chiang MF, Boland MV, Brewer A, Epley KD, Horton MB, Lim MC, et al. Special requirements for electronic health record systems in ophthalmology. Ophthalmology. 2011;118:1681-7.

26. Hwang JC, Alexander CY, Casper DS, Starren J, Cimino JJ, Chiang MF. Representation of ophthalmology concepts by electronic systems: intercoder agreement among physicians using controlled terminologies. Ophthalmology. 2006;113:511-9.
27. Lum F. Why is a terminology important? Ophthalmology. 2005;112:173-4.

28. Lee BS, Oster NV, Chen GY, Ding LL, Walker JD, Elmore JG. Ophthalmology patients' interest in online access to clinic notes at three US clinics. Ophthalmic Physiol Opt. 2017;37:420-7. https://doi.org/10.1111/opo.12367.

29. Mishra VK, Hoyt RE, Wolver SE, Yoshihashi A, Banas C. Qualitative and quantitative analysis of patients' perceptions of the patient portal experience with OpenNotes. Appl Clin Inform. 2019;10:10-8. https://doi.org/10.1055/s-00381676588.

30. Walker J, Leveille S, Bell S, Chimowitz H, Dong Z, Elmore JG, et al. OpenNotes after 7 years: patient experiences with ongoing access to their clinicians' outpatient visit notes. J Med Internet Res. 2019;21:e13876. https://doi.org/10.2196/13876.

31. Michael M, Bordley C. Do patients want access to their medical records? Med Care. 1982;20:432-5.

32. Ridsdale L, Hudd S. What do patients want and not want to see about themselves on the computer screen: a qualitative study. Scand J Prim Health Care. 1997; 15:180-3.

\section{AUTHOR CONTRIBUTIONS}

JNT, CTL, and RSD were responsible for collecting the data. JER, JNT, and AYW were responsible for reviewing published literature, analysing and interpreting data in the context of this literature, and writing the paper. JT, CTL, RSD, JP, AS, and AYW were responsible for initial design of the study.

\section{COMPETING INTERESTS}

The author declares no competing interests. RSD is a consultant for Zeiss, Allergan, Kala Pharmaceuticals, Eyepoint Pharmaceuticals, Dompé, Novartis International, and Sun Pharma.

\section{ETHICS APPROVAL}

The University of Colorado IRB and Icahn School of Medicine at Mount Sinai IRB determined that this survey study was IRB exempt. They did not provide a reference number because it was exempt.

\section{ADDITIONAL INFORMATION}

Correspondence and requests for materials should be addressed to Jake E. Radell.

Reprints and permission information is available at http://www.nature.com/ reprints

Publisher's note Springer Nature remains neutral with regard to jurisdictional claims in published maps and institutional affiliations.

Open Access This article is licensed under a Creative Commons Attribution 4.0 International License, which permits use, sharing, adaptation, distribution and reproduction in any medium or format, as long as you give appropriate credit to the original author(s) and the source, provide a link to the Creative Commons license, and indicate if changes were made. The images or other third party material in this article are included in the article's Creative Commons license, unless indicated otherwise in a credit line to the material. If material is not included in the article's Creative Commons license and your intended use is not permitted by statutory regulation or exceeds the permitted use, you will need to obtain permission directly from the copyright holder. To view a copy of this license, visit http://creativecommons. org/licenses/by/4.0/.

(c) The Author(s) 2021 